\title{
LA MUERTE Y EL SUICIDIO EN LA POESÍA DE R. M. RILKE
}

\author{
Otto Dörr Zegers \\ Profesor Titular de Psiquiatría de la Universidad de Chile. \\ Jefe del Servicio A del Hospital Psiquiátrico.
}

Correspondencia: Dr.Otto Dörr Zegers. Luis Thayer Ojeda 0115, Of.502. Providencia. Santiago. Chile 



\section{LA MUERTE Y EL SUICIDIO EN LA POESÍA DE R. M. RILKE ${ }^{i}$}

Otto Dörr Zegersi

\section{Resumen}

El suicidio sólo se puede comprender desde una reflexión previa sobre la muerte. A propósito de algunos textos de Hegel, Goethe y Heidegger, el autor recuerda la concepción de la muerte no sólo como parte de la vida, sino como lo que le da sentido. Una idea análoga, aunque expresada de un modo muy original, es la que sostiene el poeta Rainer María Rilke en una carta a su editor en polaco, W. Hulewicz, del 13 de noviembre de 1925. $\mathrm{El}$ autor intenta investigar más en profundidad el pensamiento del poeta respecto a la muerte, a través de un análisis de la Octava, Novena y Décima Elegías del Duino (1922), poesías en las cuales el poeta desarrolla su concepto de la "muerte propia", anunciado en su novela Los Cuadernos de Malte (1910). Para él la vida misma consiste en "aprender a morir", en preparar con tiempo "la obra maestra de una muerte noble..., de una muer- te consumada, feliz y entusiasta, como sólo los santos supieron concebirla". La pregunta es entonces qué puede pasar para que alguien no espere su muerte propia y destruya con su acto suicida la armonía de la vida y de la muerte. La respuesta la da el poeta en el Réquiem para Wolfvon Kalckreuth (1908). El suicida no reconoce en la tierra la posibilidad de la alegría, como la que a veces se esconde detrás de los dolores. En segundo lugar, el suicida se apresura a dar a la vida y a la muerte una interpretación definitiva, sin esperar que en el camino se nos devele el sentido de la existencia. Por último, el joven suicida de Rilke, que era un poeta, no dejó madurar su obra, quizás porque no comprendió cuál era la esencia de la poesía: que a través de ella el poeta se transforme en las palabras que eternizan las cosas.

PALABRAS CLAVE: Muerte; Suicidio; Poesía; Vida; Existencia.

Leído en las Jornadas sobre "El final de la vida", organizadas por el Programa Regional de Bioética de la Organización Panamericana de la Salud 1999.

ii Profesor Titular de Psiquiatría de la Universidad de Chile. Jefe del Servicio A del Hospital Psiquiátrico. 


\section{Resumo}

Só se pode compreender o suicídio mediante uma reflexão prévia sobre a morte. A partir de alguns textos de Hegel, Goethe e Heidegger, o autor resgata a concepção de morte como parte integrante e que confere sentido à vida. Com uma idéia análoga, ainda que expressada de maneira diversa, é a que apresenta o poeta Rainer Maria Rilke em uma carta à seu editor em polonês, W. Hulewics, datada de 13 de novembro de 1925 . O autor do presente texto pretende investigar com profundidade o pensamento do poeta a respeito da morte e o faz, através da análise da Oitava, Nona e Décima Elegias de Duino (1922). Nessas poesias, Rilke apresenta seu conceito da "morte própria" que anuncia na novela Os Cadernos de Malte (1910). Para ele a vida consiste propriamente em "aprender a morrer", em preparar com tempo "a obra-prima de uma morte nobre... de uma morte consumada, feliz e com entusiasmo, como somente os santos souberam concebêla". A pergunta que se impõe, portanto, é o que pode ocorrer com alguém que não aguarda sua própria morte e destrua pelo suicídio a harmonia da vida e da morte. A resposta a esta pergunta, o poeta apresenta no Requiem para Wolf von Kalckreuth (1908). O suicida não reconhece a possibilidade da alegria esconder-se atrás de sofrimentos. Em segundo lugar, o suicida se apressa em dar uma interpretação definitiva sobre a vida e a morte não permitindo que se desvele o sentido da existência. Finalmente, o jovem suicida de Rilke, que era um poeta, não permite que amadureça sua obra, quiçá porque não tenha apreendido a essência da poesia, já que é através dela que o poeta se transforma, é por meio das palavras que os fatos se eternizam.

\section{Abstract}

Suicide can be understood only as a result of a previous reflection about death. With reference to some texts by Hegel, Goethe and Heidegger, the author proposes a conception of death, not only as a part of life but also as 'that' that gives meaning to it. A similar idea, though expressed in a very original way, is the one sustained by the poet Rainer Maria Rilke in a letter to his editor in Polish, W. Hulewicz, of November 13, 1925. The author tries to study more deeply the poet's thought concerning death, through the analysis of the Eighth, Ninth and Tenth Duino Elegies (1922), poems where Rilke develops his concept of the "personal death", announced in his novel, The notes of Malte Laurids Brigge (1910). To him, life itself consists of "learning to die", of preparing in advance "the masterpiece of a noble death..., of a consummate, happy and enthusiastic death, as only saints were able to conceive it". Then, the question is what could happen to induce someone not to wait for his /her own death and destroy with a suicidal act the harmony of life and death?. The poet gives the answer in the Requiem for Wolf von Kalckreuth (1908). The one committing suicide does not recognize in earth the possibility of joy, as something that, sometimes, is hidden amid pain. Secondly, the suicide hurries to give life and death a definitive interpretation, without allowing life - in its own way - to unveil the meaning of the existence. Finally, Rilke's suicidal young, who happened to be a poet, did not let his work mature, perhaps he did not understand what was the essence of poetry: that the poet transforms himself in the words that eternalize things.

KEY-WORDS: Death; Suicide; Poetry; Life; Existence. 


\section{Résumé}

Le suicide ne peut se comprendre que par une réflexion préalable sur la mort. L'auteur, à partir de certains textes de Hegel, Goethe et Heidegger, rappele la conception de la mort non seulement comme partie de la vie, mais aussi comme ce que lui en donne du sens. Une idée analogue, même si elle est exprimée d'une façon très originale, c'est celle qu' exprime le poète Rainer Maria Rilke dans une lettre à son éditeur en polonais, $\mathrm{W}$. Hulewicz, du 13 de Novembre, 1925. L'auteur essaie de chercher la pensée du poète à propos de la mort, à travers une analyse de Octava, Novena y Décima Elegias del Duino, (1922), des poésies dans lesquelles le poète développe son idée de la "mort propre", déjà annoncée dans son roman, Los Cuadernos de Malta (1910). Pour le poète la vie consiste dans un' "apprendre à mourir", préparer avec du temps "l'oeuvre maîtresse d'une morte noble..., d'une mort consommée, heureuse et passionnée, comme seulement les saints ont su la conçevoir". Alors, la question que se pose est celle de savoir qu'est-ce que peut arriver pour que quelqu'un n'attende pas sa propre mort et avec un acte suicide détruise l'armonie de la vie et de la mort. La réponse est donnée par le poète dans le Réquiem pour Wolf von Kalckreuth (1908). Le suicidé ne trouve pas dans la terre la posibilité de la joie, comme celle que parfois est cachée derrière les souffrances. En second lieu, le suicidé est pressé à donner à la vie et à la mort une interprétation définitive, sans attendre que dans le chemin se dévoile le sens de l'existence. Finalement, le jeune suicide de Rilke n'a pas laissé mûrir son oeuvre, peutêtre parce qu'il n'a pas compris quelle était l'essence de la poésie: Ce n'est qu' à travers celle-ci que le poète se transforme dans des mots qu' éternisent les choses.

MOTS CLÉS: Mort; Suicide; Poésie; Vie; Existence. 
El suicidio significa interrumpir violentamente ese proceso natural que es el morir. La muerte es el fin de la vida, pero no al modo de un terminar cualquiera, como termina un camino o una melodía, por cuanto la muerte pertenece a la vida. No hay vida sin muerte, porque ésta nos da, entre otras cosas, la posibilidad del tiempo. El tiempo se constituye desde la finitud, desde la muerte, y su carácter central es la transitoriedad. Y, como dice Heidegger (1), "la muerte es la más propia (auténtica) posibilidad de la existencia... Es (justamente) el ser-relativamente-a-lamuerte el que abre a la existencia su más propio poder-ser." Este concepto de la muerte como parte esencial de la vida ya lo encontramos en el principio Stirb-Werde de Goethe (2), que podría traducirse como "morir para llegar a ser" y también en todo el pensamiento dialéctico de Hegel (3). Recordemos ese famoso pasaje de la Introducción a la Fenomenología del Espíritu: "El botón desaparece con el surgimiento de la flor y se podría decir que aquél es negado por ésta; del mismo modo el fruto transforma a la flor en una falsa existencia de la planta, pues aparece en lugar de la flor como la verdadera planta...", etc.

Dicho con otras palabras, la muerte del botón significa la vida de la flor, la muerte de la flor significa la vida del fruto y así sucesivamente. Vida y muerte se entrelazan inextricablemente. Habría algo así como una muerte inmanente a la vida y que sería como su elemento transformador, eso que permite, en un sentido dialéctico, el paso a una nueva síntesis.

Algo semejante encontramos en uno de los poetas que más se ha preocupado del tema de la muerte: Rainer Maria Rilke. En una carta del 13 de noviembre de 1925 a su editor en polaco, Wietold Hulewicz (4), — quien le había preguntado sobre el sentido último de las Elegías del Duino, uno de los grandes monumentos de la poesía universal-Rilke escribe: “...Las elegías conducen a la demostración de que esta vida, así suspendida sobre el abismo, es imposible. En las elegías... la vida se hace otra vez posible... (pues) la aceptación de la vida y de la muerte se nos muestra como una misma cosa... la muerte es el lado de la vida apartado y no iluminado por nosotros. Tenemos que hacer el intento de alcanzar la máxima conciencia de nuestra existencia, la que está domiciliada en ambos ámbitos ilimitados y se nutre de ambos inagotablemente... No hay ni un allende ni un aquende, sino la gran unidad en la cual también habitan los seres que lo superan, los ángeles...". Y más adelante, en la misma carta, explica con mayor detalle lo que quiere decir con su concepto de la unidad de la vida y de la muerte: “....Nosotros, los de aquí y ahora, no estamos ni un momento satisfechos en este mundo temporal, pero tampoco estamos atados a él, sino que pasamos permanentemente hacia el mundo anterior, hacia nuestro origen, como también hacia el mundo ulterior, el de aquellos que vendrán después de nosotros. En aquel máximo 'mundo abierto' existen todos... (Aquí) no me estoy refiriendo (estrictamente) al sentido cristiano... Con una conciencia puramente terrena, profundamente terrena, beatamente terrena, hay que introducir lo aquí visto y tocado en un círculo más amplio, en el más amplio posible. No en un 'más allá', cuya sombra oscurece la tierra, sino en una totalidad, en lo entero...". Por último, el poeta le explica a su editor cuál es, mientras vivimos, nuestra relación con el resto de las cosas de este mundo, que comparten con nosotros la provisionalidad, pero que desconocen la muerte: "La naturaleza, las cosas de nuestro trato cotidiano y de nuestro uso son, mientras estamos aquí en la tierra, nuestra propiedad y nuestra amistad; ellas son consabidoras de nuestra alegría y de nuestra miseria y ya fueron los confidentes de nuestros antepasados. Así, no sólo no hay que descalificar y degradar lo de aquí, sino que precisamente por su provisionalidad... estas apariencias y estas 
cosas tienen que ser comprendidas y transformadas por nosotros... ¿Transformarlas?, sí, porque nuestra tarea es ésta, impregnarnos de esta tierra provisional y caduca tan profundamente, tan dolientemente, tan apasionadamente, que su esencia resurja otra vez en nosotros, invisible. Somos las abejas de lo invisible... Las elegías nos muestran a nosotros en esta tarea, en la tarea de este constante transformar lo amado, visible y tangible, en la oscilación y la agitación invisibles de nuestra naturaleza; y esto va a introducir nuevas formas de vibración en... el universo..." (op. cit., p. 374 ss.).

Nos hemos detenido un momento en este impresionante texto de Rilke y escrito, como toda carta, "al correr de la pluma", porque creemos encontrar en él no sólo una visión positiva de la muerte, sino, y sobre todo, una suerte de llamado a una misión de vida que sería ineludible: el amar las cosas y, a través de la palabra, eternizarlas. Para las citas de los textos poéticos emplearemos una traducción del alemán hecha recientemente por nosotros (5). Y así el poeta nos dice en la Novena Elegía (6):

"...y estas cosas

que viven de la muerte comprenden que tú las elogies; ellas, las fugaces,

confían en que nosotros, los más efímeros, seamos capaces de salvarlas.

¡Ellas quieren que las transformemos del todo en un corazón invisible

-oh infinitamente- en nosotros!, quienquiera que seamos al final..."

Y las cosas están ahí esperando que nosotros, los humanos, procedamos a transformarlas, a hacerlas invisibles, pero no sólo a la casa, el cántaro o el manantial, como dice el poeta un poco antes, al descubrir que nuestra primera misión en la tierra es el dar un nombre a las cosas, sino a todas las cosas, más aún, a la tierra entera, algo que manifiesta expresamente en el verso siguiente:
"Tierra, ¿no es esto lo que tú quieres: resurgir en nosotros

invisible? ¿No es tu sueño ser invisible alguna vez?

¡Tierra! ¡Invisible! ¿cuál, si no metamorfosis, es tu apremiante misión?..."

Con esta hermosa misión el hombre puede ir tranquilo al encuentro de la muerte, que, por lo demás, sólo él conoce. Es cierto que este conocimiento es la fuente última de la angustia - dolorosa emoción que lo acompaña durante casi toda su existencia- pero puede que constituya también su mayor grandeza. Ni los animales ni los ángeles conocen la muerte. "El animal libre (de la muerte) / tiene tras sí su ocaso / y ante sí a Dios y, cuando camina, entonces / lo hace hacia la eternidad, así como manan las fuentes", como dice el poeta en la Octava Elegía. Mientras los ángeles tampoco saben de ella, porque viven "en el torbellino de su (permanente) retorno a sí mismos" (Segunda Elegía). ¿Qué puede ocurrir para que alguien no espere su muerte propia y destruya con su acto suicida la armonía de la vida y de la muerte? Una posibilidad es pensar que el suicida olvida que el dolor es "nuestro follaje / invernal y perenne, nuestro verdor oscuro del sentido, / una de las estaciones del año secreto, mas no sólo tiempo, / sino lugar, poblado, campamento, suelo, residencia”. Es decir, el dolor lo es todo y es tan consubstancial a la vida humana, que es de las pocas cosas que legítimamente podemos llevarnos al más allá. Rilke expresa maravillosamente este pensamiento en la Novena Elegía, cuando dice:

“...¿qué se lleva uno hacia el más allá? No el mirar, aquí

lentamente aprendido, y nada de lo que aquí ocurrió. Nada.

Pero sí los dolores. Sobre todo la pesadumbre,

también la larga experiencia del amor: es decir,

todo lo inefable..." 
Nuestra misión es salvar las cosas a través de la palabra, darles un sentido, eternizarlas. Pero de todo lo que hemos vivido en esta tierra, lo único que podemos llevarnos hacia el más allá, para que así nos acompañe eternamente, es para el poeta un extraño bagaje, compuesto sólo de dos elementos: el sufrimiento y el amor. El acto de suicidarse significa entonces desconocer el valor del sufrimiento y el sentido del amor. Rilke se refirió expresamente al tema del suicidio en el Réquiem para el Poeta Wolf von Kalckreuth (7). Intentaremos resumir algunas de las ideas sobre el tema que se desprenden de este maravilloso poema. No se conocen las razones que tuvo el joven poeta para suicidarse, pero Rilke le reprocha a lo largo de todo el réquiem el que no haya sido capaz de perseverar, esperando que le llegase su propia muerte. Porque Rilke no estaba en contra de la muerte de los jóvenes; por el contrario, en la muerte prematura del héroe y en el profundo misterio que encierra la muerte infantil él cree encontrar un camino legítimo para el hombre elegido. Pero el suicidio lo perturba profundamente. El primer reproche que le hace a Kalckreuth es el no haber reconocido en la tierra la posibilidad de la alegría, la que a veces se esconde detrás de los dolores; más aún, en el momento menos pensado el sufrimiento se invierte, dando paso al consuelo y aún a la felicidad:

"Lo que no esperaste fue que el peso

se hiciese del todo insoportable: es entonces cuando éste

se invierte de repente y es tan pesado por ser tan verdadero.

Ves, éste fue quizás tu momento más cercano;

tal vez él se acomodaba la guirnalda en el cabello

ante la puerta que tú le cerraste bruscamente."

Luego de una serie de consideraciones sobre lo poco que sabemos sobre el misterio de la existencia y cómo no debemos adelantarnos a darle una interpretación definitiva, como la que resulta de un acto como el suicidio, el poeta se conduele de que no haya habido alguien en las cercanías del joven suicida que le hubiese podido hacer cambiar su decisión:

"Si una mujer hubiese puesto su mano ligera

sobre el comienzo aún delicado de esta ira;

si hubiera habido alguien, que estando ocupado,

ocupado en lo más íntimo, te hubiese encontrado

quedamente cuando tú, mudo, saliste a consumar la acción;

si tu camino hubiera conducido

cerca de un taller despierto,

donde hay hombres martillando, donde el día se realiza

simplemente..."

Ahora, dada su muerte prematura, muy pocas cosas dejó el joven conde: sólo algunos poemas imperfectos ("somos espectadores sólo de los poemas que hacia abajo traen / las palabras que tú escogiste"), pero en ellos Rilke reconoce al menos dos virtudes: una es la inspiración, venida casi directamente del mundo angélico ("a menudo un comienzo se te imponía como un todo / un comienzo que tú repetías como una orden"); la otra es que el joven poeta, a través de sus poemas llegó a "ver", a "reconocer la renuncia y en la muerte tu progreso". Aquí Rilke acepta por primera vez la posibilidad de que la muerte del joven poeta haya tenido un sentido.

Hacia el final del réquiem Rilke trata de definir en apretadas palabras lo que debe ser la esencia de la vida poética. Ésta debe alimentarse fundamentalmente de los siguientes ingredientes ("tres formas abiertas"): los sentimientos verdaderos, el mirar (que mira y ve, pero que "no desea nada") y "la muerte trabajada", esa muerte propia que tanto nos 
necesita. La verdadera poesía debe ser un trabajo de la propia vida y de la propia muerte y yo agregaría que quizás toda vida humana, no sólo la vida poética, debería consistir en lo mismo. El poeta adolescente no dejó brotar la vida, con todo lo que ella puede regalarnos, pero tampoco fue capaz de esperar su propia muerte. Y entonces Rilke retoma el tema de la esencia de la poesía, anunciado ya en las Cartas de un joven poeta, diciendo que éstos, en lugar de quejarse, deberían "decir" (cosas esenciales), que en lugar de juzgar tanto sus sentimientos deberían "darles forma"; que deberían, por último, transformarse ellos mismos en palabras ("como el cantero de una catedral / que con obstinación se convierte en la serenidad de la piedra"). Y esto habría sido la salvación del Conde Kalckreuth, pero él no la vio, a pesar de haberla tenido en sus manos. Habría bastado que hubiera comprendido la esencia de la poesía. Pero ahora todo esto son palabras vanas. No sea que el adolescente al escucharlas se avergüence entre los muertos y que las lamentaciones de los vivos agraven sus sentimientos de culpa. Y el réquiem termina con una recomendación a asumir el destino con todas sus consecuencias, incluyendo los errores, pues: "¿Quién habla de victorias? El resistir lo es todo".

El tema que nos ha reunido es "El fin de la vida". Y el fin de la vida es la muerte en un doble sentido: como término de nuestra existencia en este mundo, pero al mismo tiempo, como lo que le da el sentido. En el libro Cartas a una amiga veneciana (8) Rilke afirma: "Hay que aprender a morir. En eso consiste la vida, en preparar con tiempo la obra maestra de una muerte noble y suprema, una muerte en la que el azar no tome parte, una muerte consumada, feliz y entusiasta como sólo los santos supieron concebirla...".

No sé si estas reflexiones puedan servir de algo a quien ya se encuentra con una enfermedad terminal en las proximidades de la muerte, pero quizás si la lucidez de este gran poeta nos pueda ayudar a nosotros, a los médicos llamados a asistir a estos enfermos; pues, aun cuando todavía no seamos "terminales", desde que fuimos conscientes de lo que significa nuestra profesión, hemos tenido que acostumbrarnos a la idea de que pertenece esencialmente a nuestra condición humana el vivir desahuciados.

\section{Referencias:}

1. Heidegger M. Sein und Zeit [1927]. Tübingen: Max Niemayer Verlag; 1963.

2. Goethe JF. Werke Briefe und Gespräche. Gedenkausgabe Band XVII: Naturwissenschaftliche Schriften. Zürich und Stuttgart: Artemis Verlag; 1966.

3. Hegel G F. Phänomenologie des Geistes. Hamburg: Felix Meiner Verlag; 1952.

4. Rilke RM. Briefe 2. Band [1919-1926]. Frankfurt am Main: Insel Verlag; 1999.

5. Dörr-Zegers, O. Traducción, Prólogo, Notas y Comentarios. En: Rilke RM. Diez elegías, tres réquiem y una canción de amor. Madrid: Editorial Visor. En prensa.

6. Rilke R M. Duineser Elegien. In: Sämtliche Werke. Band I. Frankfurt am Main: Insel Verlag; 1955.

7. Rilke R M. Requiem für Wolf Graf von Kalckreuth. In: Sämtliche Werke. Band I. Frankfurt am Main: Insel Verlag; 1955.

8. Rilke R M. Cartas a una amiga veneciana. Madrid: Hiperión; 1993. 